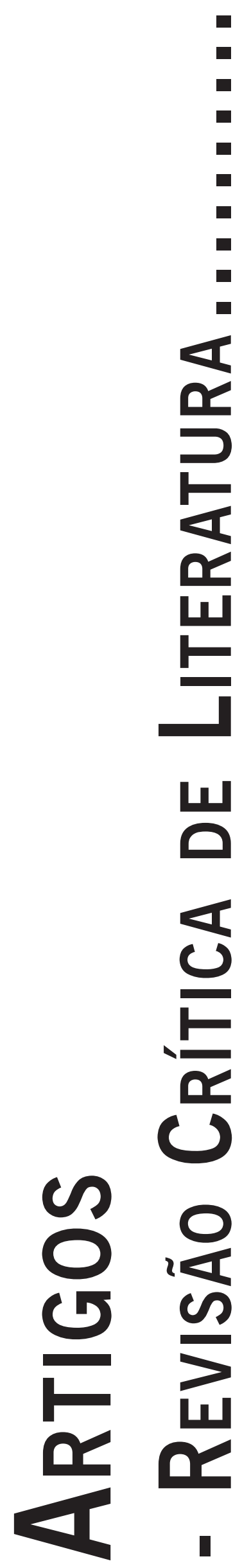




\title{
EM BUSCA DE UMA BOA FORMA DE FAZER PSICOLOGIA DO ESPORTE': CONTRIBUIÇÕES DA GESTALT-TERAPIA
}

\author{
In Search of a Good Way of Applying Sport Psychology: Contributions of Gestalt-therapy \\ En Busca de una Buena Manera de Hacer Psicología del Deporte: \\ Contribuciones de la Terapia Gestalt
}

Adriana Amaral do Espírito Santo

\begin{abstract}
Resumo: Este artigo busca apresentar a psicologia do esporte a partir de uma abordagem que ainda é raramente utilizada neste campo, embora já esteja consolidada no âmbito da psicologia há muitas décadas: a gestalt-terapia. Assim, inicialmente apresenta, em linhas gerais, em que consiste a atuação do psicólogo do esporte para, a partir daí, pensar este trabalho à luz do referencial gestáltico. O foco se dá sobre dois níveis cruciais da intervenção: a compreensão diagnóstica e a intervenção propriamente dita. $\mathrm{O}$ artigo aborda o esporte individual de alto rendimento, visto que a psicologia do esporte é extremamente ampla e não haveria como dar conta de todas as suas possibilidades de intervenção num único artigo.

Palavras-chave: Psicologia do esporte; Gestalt-terapia; Intervenção psicológica.

Abstract: This article aims to present the sports psychology from an approach that is still rarely used in this field, although it has been part of psychology for several decades: the gestalt therapy. Therefore, it presents initially, in general words, what is the psychology practice in sports and, from this point, it takes into consideration this work through the gestalt-therapy theory. Its focus consists of two crucial moments of intervention: diagnosis and intervention itself. The outline of the article is based on the individual sport high-performance, as the sports psychology is extremely wide and it would be impossible to cover all the possible interventions in a single article.

Keywords: Sport psychology; Gestalt therapy; Psychological intervention.

Resumen: Este artículo tiene como objetivo presentar la psicología del deporte desde un enfoque que aún se utiliza muy poco en este campo, a pesar de estar consolidado en el contexto de la psicología desde hace muchas décadas: la terapia gestalt. Por lo tanto, presentase inicialmente, en líneas generales, en que consiste el trabajo del psicólogo del deporte, desde aqui, pensando en este trabajo sobre el prisma del referencial gestalt. El enfoque se da al respecto de dos momentos cruciales de la intervención: el diagnóstico y la intervención propiamente dicha. El recorte de este artículo se situa en el deporte individual de alto rendimiento, ya que la psicología del deporte es muy amplia y no hay manera de explicar todas las posibilidades de intervenir en un solo artículo. Palabras clave: Psicología del deporte; Terapia de gestalt; Intervención psicológica.
\end{abstract}

No final do século XIX, começaram a desenvolver-se, nos Estados Unidos e Europa, tentativas científicas de melhorar a performance de atletas de alto rendimento nos mais variados aspectos, inclusive o psicológico. De lá para cá, o que se consolidou como Psicologia do Esporte se desenvolveu, tanto no campo da pesquisa quanto no da intervenção, sendo cada vez mais compreendido como um fator importante para o bom desempenho no esporte de alto nível. No Brasil, é de João Carvalhaes aquele que é considerado como o primeiro trabalho na área, na década de 1950, em São Paulo, culminando em sua atuação mais conhecida, com a seleção brasileira de futebol masculino que foi campeã mundial em 1958, na Suécia.1

Por volta da década de 1970, há registros de alguns trabalhos em clubes. Também foram publicadas obras importantes, como Psicologia esportiva e preparo do atleta, de Athayde Ribeiro da Silva, em 1967; Psicologia dos es-

\footnotetext{
Alusão ao capítulo "Em busca de uma boa forma de descrever o trabalho em Gestalt”, Juliano, J. C. (1999). A arte de restaurar histórias. (p. 25-35). São Paulo: Summus.
}

portes, de R. Haddock Lobo, em 1973; Um psicólogo no futebol: relatos e pesquisas, de João Carvalhaes, em 1974. Em 1979, foi criada a Sociedade Brasileira de Psicologia do Esporte (SOBRAPE), posteriormente denominada Sociedade Brasileira de Psicologia do Esporte, Atividade Física, Recreação e Lazer. Desenvolveram-se ainda alguns congressos, contribuindo para um primeiro grande momento produtivo no Brasil.

Nesse, que pode ser considerado um dos períodos mais marcantes da Psicologia do Esporte em nosso país, paralelamente, era introduzida a Gestalt-terapia. Juliano (2004) aponta 1972 como o ano de introdução do movimento gestáltico no Brasil, após viagem de Thérèse Tellegen a Londres, onde travou contato com a nova abordagem. Naquele mesmo ano, ela publicou Elementos de Psicologia Gestáltica, no Boletim de Psicologia da Sociedade de Psicologia de São Paulo. Nos anos subsequentes, diversos outros acontecimentos foram se desenrolando. Em 1973, Silvia Peters realizou um workshop de 12 horas em São Paulo, no Grupo de Estudos de Psicologia So- 
cial Aplicada (GEPSA) (Esch, 2012). O primeiro grupo de formação, em 1978, foi conduzido por Walter Ribeiro e outros profissionais de diferentes lugares do Brasil, originando, posteriormente, o primeiro curso de "Especialização na Abordagem Gestáltica em Psicoterapia”, no Instituto Sedes Sapientiae (Prestrelo, 2001, p. 92). Houve, ainda, a publicação de diversos livros da área, em sua maioria traduções, como mostra Esch (2012) em seu detalhado estudo histórico sobre este período. Entre eles: Gestalt-terapia explicada (1977), com prefácio de Thérèse Tellegen, Isto é Gestalt (1977) e Escarafunchando Fritz (1979). Além disso, revistas, teses e dissertações sobre o assunto começaram a surgir no país ${ }^{2}$.

Esta coincidência temporal, no entanto, não fez com que as duas áreas caminhassem juntas. Ao observarmos desde os trabalhos mais iniciais até a profusão de profissionais existentes hoje na área do esporte e da atividade física, é possível perceber, empiricamente, que a maioria deles trabalha fundamentada na abordagem cognitivo-comportamental. Existe uma outra parcela de psicólogos que se intitulam adeptos de diversas abordagens, como psicanálise, psicodrama e pedagogia da cooperação. Há, ainda, muitos que utilizam referências diversificadas, por vezes até misturando abordagens quase que antagônicas, como o aconselhamento psicológico rogeriano, psicanálise, fenomenologia, gestalt-terapia, psicopatologia, etologia humana, psicologia institucional, biologia e subáreas das Ciências do Esporte (Espírito Santo, 2005).

No que diz respeito à abordagem gestáltica, encontramos apenas um artigo, em inglês, sobre o trabalho com uma atleta da modalidade orientação (Bednarova, 2009). Outro artigo relacionado a aspectos práticos da atividade vem não da gestalt-terapia, mas da fenomenologia (Frascarelli, 2010). Também no campo da fenomenologia, atualmente existe, na cidade de Petrolina (PE), o Núcleo de Estudos e Pesquisas em Fenomenologia e Esporte (NEPFE), da Universidade Federal do Vale do São Francisco (UNIVASF), o que mais se aproxima da proposta gestáltica no cenário brasileiro.

Consideramos que por trás da abordagem psicológica - fundamentalmente clínica - deve estar o conhecimento do fenômeno esportivo, da história e sociologia do esporte, enfim, todo um embasamento que permita compreender o atleta naquele contexto. Contudo, entendemos que a escolha da abordagem traduz a visão de homem do psicólogo e vai nortear sua compreensão e suas intervenções em qualquer que seja seu campo de atuação.

Assim, neste artigo buscamos trazer para dentro do contexto esportivo o olhar da Gestalt-terapia, entendida como uma forma de ser e estar no mundo e de entendê-lo sob uma ótica particular e ainda escassa na literatura brasileira de Psicologia do Esporte. Vale lembrar que praticamente todas as abordagens psicológicas surgiram no âmbito da clínica, tendo sua teoria voltada para o aten-

\footnotetext{
Para informações detalhadas sobre as publicações neste momento histórico da gestalt-terapia no Brasil, indico o trabalho de Esch (2012).
}

dimento em consultório, numa época em que a própria Psicologia não ia muito além desta aplicação. Mais recentemente, com a expansão da profissão em diversas áreas de existência do ser humano, as diferentes abordagens puderam também ser ampliadas e aplicadas nos mais diversos meios. Hoje, a Gestalt-terapia, assim como todas as abordagens, já é utilizada em vários campos de atuação do psicólogo, como o hospital, a escola, a justiça e, por que não, o esporte.

Yontef (1998) já afirmava, com relação à clínica, que a Gestalt-terapia poderia ser usada eficazmente com qualquer população e qualquer grupo imaginável, desde que o terapeuta conseguisse entendê-lo e sentir-se à vontade. Este raciocínio pode ser aplicado a todos os outros campos, como os que citamos anteriormente, não impedindo uma prática, oriunda na clínica, de ser adaptada a outras possibilidades de intervenção.

Antes de prosseguirmos, contudo, é necessário pontuar de que Psicologia do Esporte iremos tratar aqui. Hoje, ela é muito mais do que apenas o alto rendimento, abrangendo outras formas de prática esportiva e também a atividade física. Rubio (2007b) descreve, em uma divisão didática, as seis principais áreas de atuação do psicólogo do esporte: alto rendimento, reabilitação, projetos sociais, iniciação esportiva, esporte escolar e práticas de tempo livre. Cada uma possui suas especificidades e seria infrutífero tentar dar conta de todas neste momento. Por isso, consideramos aqui o esporte individual adulto de alto rendimento, entendendo como individual também o acompanhamento isolado de um atleta de uma modalidade coletiva.

Para este fim, iniciamos com uma apresentação sobre em que se constitui o trabalho do psicólogo do esporte, em linhas gerais, independentemente de sua linha teórica. A partir daí, concentramos as atenções sobre os dois momentos cruciais deste trabalho - o diagnóstico e a intervenção -, relacionando os principais conceitos da Gestalt-terapia à atuação no esporte, explorando o diferencial que acreditamos que a abordagem oferece. Para ilustrar, apresentamos brevemente alguns exemplos extraídos da prática profissional ${ }^{3}$, cientes de que, por vezes, eles podem limitar a compreensão do fenômeno, mas também acreditando que, devido à escassez de trabalhos correlacionando gestalt-terapia e psicologia do esporte, é assim que poderemos apresentar de forma mais clara como acontece o dia-a-dia do trabalho.

\section{0 trabalho em Psicologia do Esporte}

Embora hoje já se saiba que houve primórdios de uma Psicologia voltada para o esporte por volta da década de

\footnotetext{
Os exemplos apontados neste artigo advêm de situações reais de trabalho e foram redigidos sem qualquer possibilidade de identificação dos envolvidos, motivo pelo qual não foi necessário solicitar sua autorização explícita.
} 
1930, o marco deste trabalho, no Brasil, ainda permanece sendo a atuação de João Carvalhaes. Em 1954, ele iniciou sua atuação como psicólogo junto à Federação Paulista de Futebol, realizando a seleção de árbitros. Trabalhou ainda como comentarista de lutas de boxe, porém se fixou mesmo no futebol: ainda na década de 1950, atuou no São Paulo Futebol Clube e na seleção brasileira de futebol que se sagrou campeã da Copa do Mundo de 1958, na Suécia.

De lá para cá, esta prática veio se expandindo, com diversas inserções, em especial em equipes de futebol. Atualmente, existe uma ampla gama de possibilidades para além dos gramados, como golfe, surfe, esportes de aventura, além daqueles esportes mais conhecidos, como vôlei, basquete ou natação. Esta diversidade pode ser constatada, por exemplo, pela observação dos perfis dos psicólogos atuantes que constam no site da Associação Brasileira de Psicologia do Esporte (ABRAPESP) (www. abrapesp.org.br).

No entanto, muito deste trabalho ainda carrega um ranço histórico, focado prioritariamente no rendimento e na identificação de atletas-problema. Para Frascareli (2010), esta é uma visão limitada, cientificista, que traz na suposição de um problema psicológico a cisão entre corpo e mente. A autora entende a psicologia do esporte como algo mais amplo, que cuida do humano. Isso inclui, obviamente, os problemas de rendimento, mas vai além, auxiliando o atleta a entrar em contato consigo e a crescer. Nessa medida, o psicólogo do esporte deve ser preparado para ouvir o atleta, sem procurar nele apenas "problemas que estejam atrapalhando o rendimento” (p. 123).

Weinberg e Gould (2008) discriminam três possibilidades de orientação do trabalho do psicólogo do esporte: psicofisiológica, sociopsicológica e cognitivo-comportamental. A primeira enfatiza os processos fisiológicos do cérebro e sua influência sobre a prática esportiva. A orientação sociopsicológica percebe as interrelações entre o comportamento, a personalidade e o ambiente. Já o terceiro tipo não desconsidera as relações com o ambiente, mas enfatiza as cognições e pensamentos influenciando o comportamento, trabalhando bastante com psicometria.

Já Ducasse (2006) possui uma compreensão mais holística do atleta, construindo ferramentas para entendê-lo e ajudá-lo a refinar suas formas de pensar, sentir e agir em todos os aspectos de sua vida. Para o autor, as técnicas de condicionamento são limitadas e podem promover um pensamento simplista, quando na verdade "o psicológico vem do que é vivido, não de uma fórmula” (p. 36). Assim, Ducasse recorre, por exemplo, à metáfora do "mapa do psicológico”, comparando o caminho para o sucesso a uma cartografia, e desenvolve meios para melhor atingir as metas pessoais, como o planejamento individualizado da caminhada através deste mapa.

Para Markunas (2003), há uma distinção entre treinamento psicológico e preparação psicológica. $\mathrm{O}$ primeiro consiste na aplicação de técnicas e exercícios, objetivando o ensino, formação e desenvolvimento de habilidades psicológicas, como concentração e treino mental. Já a preparação psicológica abarca o treinamento psicológico, mas vai além, abordando o atleta de maneira global, ajudando-o a encontrar ferramentas próprias para o enfrentamento das diversas situações com que irá se deparar em sua vida esportiva. Compreende ainda a formação pessoal e moral do atleta, sua qualidade de vida antes, durante e após as competições e por toda sua vida esportiva.

Por meio de um programa de preparação psicológica, diversos aspectos serão levados em conta como a formação escolar e as influências familiares, por exemplo, sendo essencial, então, analisar e auxiliar no desenvolvimento de características pessoais e modos de enfrentamento pertinentes à prática esportiva, além de discutir as peculiaridades da modalidade escolhida em relação ao contexto existencial do atleta. (Markunas, 2003, p. 42-43)

Desse modo, trataremos neste artigo de um programa de preparação psicológica que, em qualquer que seja a abordagem, segue algumas linhas gerais, divididas em quatro fases: 1) contato inicial; 2) avaliação diagnóstica; 3) intervenção; 4) avaliação dos resultados. Estas fases não são estanques, interrelacionando-se todo o tempo, porém, por possuírem algumas ações sistemáticas que auxiliam o trabalho interdisciplinar, optamos por manter esta classificação didática da psicologia do esporte.

O contato inicial serve como cartão de visitas. É quando o psicólogo vai se apresentar, fazer um contrato de trabalho, estabelecer as primeiras interações com dirigentes, comissão técnica e atletas, obter as primeiras impressões sobre a instituição. É importante, neste momento, esclarecer sobre qual é sua função ali, para não incorporar demandas que não possa atender. Tirar dúvidas e estabelecer vínculos também fazem parte deste momento, além de informar sobre os limites e possibilidades de sua atuação, considerando inclusive o momento esportivo em que é contratado.

Sem dúvida, muitos elementos deste contato inicial servirão para a avaliação, que é realizada, sistematicamente, num momento posterior, embora seja efetivamente desenvolvida durante todo o trabalho. A fase inicial de avaliação serve para a construção de um mapa dos problemas, do modo de funcionamento, das relações interpessoais, enfim, do que funciona e o que não funciona naquele campo. Diversos recursos podem ser utilizados neste momento, como veremos adiante: desde a simples observação até a utilização de testes psicológicos ou qualquer outra ferramenta que o psicólogo julgue necessária para a coleta de informações.

Para esta etapa transcorrer sem muitos percalços, é importante que o contrato, no momento anterior, tenha sido bem estabelecido, pois quando falamos em avaliação não raramente lidamos com desconfiança, fantasias persecutórias, medo da exposição. O objetivo principal 
desta análise é obter dados para que a intervenção seja bem feita, pois não há modelos predeterminados de como trabalhar com um atleta.

Uma boa avaliação diagnóstica é fundamental para uma intervenção efetiva. Se esta focar outras questões que não as necessidades daquele atleta, não alcançará resultados eficazes. Nesse sentido, inúmeros recursos podem ser utilizados no decorrer do trabalho, a partir do levantamento de demandas que foi realizado. Resultados mais concretos são obtidos a longo prazo, porém o planejamento da intervenção pode e deve ser feito acompanhando o cronograma de competições do atleta e a periodização de seu treinamento físico e técnico, estabelecendo objetivos distintos para cada etapa, considerando que esferas psicológicas serão trabalhadas em cada fase determinada pelo treinador (Brandão \& Casal, 2007; Markunas, 2003).

Na Etapa Geral, os objetivos indicam uma orientação para a formação e desenvolvimento de uma disposição/estado no atleta. Na Etapa Específica busca-se aperfeiçoar as qualidades desenvolvidas. Na etapa seguinte (Pré-competitiva), os objetivos gerais remetem ao aprofundamento ou fortalecimento das qualidades e estados em andamento visando à etapa seguinte que representa a competição propriamente dita. (Markunas, 2003, p. 52)

Assim, a intervenção pode ser delineada para um ano, uma temporada, uma competição específica. Esta periodização do trabalho auxilia a análise dos resultados, pois permite a constante avaliação da metodologia empregada e dos resultados obtidos. Os métodos escolhidos levarão em conta as possibilidades de intervenção no momento em que o atleta ou equipe se encontra: os objetivos serão distintos num atleta ou equipe em pré-temporada, por exemplo, comparando-se com um atleta ou equipe no meio de uma competição importante. Numa pré-temporada, podem ser trabalhadas questões mais amplas, de base, como relacionamentos de grupo, confiança, planejamento de metas. Já quando se está no meio de uma competição, o foco é bem mais estreito, com questões como ansiedade pré-competitiva, análise do resultado numa etapa da competição para que o atleta possa seguir na mesma com melhor rendimento, problemas específicos de comunicação. Este delineamento é fundamental, pois na avaliação do trabalho o objetivo inicial deve ser considerado e o psicólogo, muitas vezes, é obrigado a lidar com suas limitações.

Consideramos pelo menos duas justificativas importantes para a etapa da avaliação sistemática de resultados: 1) como trabalhamos com material subjetivo, num meio acostumado a dados palpáveis e estatísticos, a avaliação final possibilita verificar as efetivas mudanças ocorridas, com base na avaliação prévia que foi realizada. 2) A partir destes resultados, é possível perceber o que mudou, o que continua da mesma forma, o que melhorou e o que piorou, enfim, as intervenções que tiveram êxito e as que não surtiram efeito. Com base nestas informações um novo ciclo de trabalho é programado.

Como podemos perceber, as fases destacadas aqui se referem a momentos sistemáticos, marcados por alguma ação mais específica do psicólogo considerando o diálogo com a instituição e os demais profissionais com os quais possivelmente irá trabalhar. Sabemos que numa proposta gestáltica não existe esta divisão estanque das etapas, pois o acompanhamento se constitui num processo dinâmico. No entanto, para fins estritamente didáticos, consideramos útil esta divisão, entendendo assim que as fases um e quatro fornecem as bases para o trabalho, mas é efetivamente no diagnóstico e na intervenção que as coisas acontecem. É por este motivo que convidamos o leitor a acompanhar mais detalhadamente, a partir deste ponto, esses dois aspectos da intervenção.

\section{Um esboço do pensamento diagnóstico em gestalt- terapia no esporte}

Uma das bases para o trabalho do psicólogo é a avaliação diagnóstica. Assim também acontece no esporte. Lembramos, contudo, que na abordagem gestáltica a compreensão diagnóstica é processual: "é uma atividade sem ponto-final” (Pinto, 2015). Assim, este momento inicial mostra-se importante numa primeira aproximação com o atleta, no qual o psicólogo dedica uma grande parte do seu tempo inteirando-se sobre a modalidade, as rotinas, as repetições, as interações, os conflitos. Deste primeiro panorama, colhe as informações para sua intervenção inicial.

Portanto, falar em diagnóstico, neste caso, significa esboçar uma primeira compreensão do atleta, sem buscar classificá-lo ou determinar técnicas para o trabalho, mas sim entender seus mecanismos de funcionamento e ajudá-lo a crescer. E é justamente o resultado deste trabalho que fará com que o diagnóstico seja dinâmico, temporário e por isso deva ser feito durante todo o acompanhamento. Como lembra Pinto (2015): "um psicoterapeuta, agindo de maneira fenomenológica, não está impedido de fazer uma compreensão diagnóstica de seu cliente (antes pelo contrário), mas está definitivamente proibido de fechar este diagnóstico" (p. 30-31).

Esta compreensão diagnóstica está ancorada nas bases filosóficas da Gestalt-terapia. Sabemos que diversas teorias a sustentam, como a Psicologia da Gestalt, a Teoria Organísmica de Kurt Goldstein, as filosofias orientais, entre outras. Yontef (1998), contudo, aponta como conceitos básicos sua perspectiva fenomenológico-existencial, a teoria de campo e a relação dialógica. Uma intervenção que careça de algum destes parâmetros pode ser o mero uso de técnicas, mas não pode ser considerada gestalt-terapia, pois é essa base que norteia a compreensão do ser humano pelo gestalt-terapeuta. 
Como lembra Ribeiro (1985), "fenomenologia é uma filosofia, é uma metodologia, implica em uma específica visão do mundo" (p. 42). A Gestalt-terapia se utiliza deste método fenomenológico para trabalhar com o presente, com o que aparece, sem pré-julgamentos e a prioris e trabalhando a partir da experiência do outro. Assim, a fenomenologia, aliada à perspectiva existencialista, permite a visão única do indivíduo, sem rótulos, sem generalizações. A Gestalt-terapia vê o homem como sendo potencialmente capaz e em constante processo de mudança. Cada um constrói sua própria existência, a partir de sua consciência.

A consciência é viva, ativa e sempre visa algo, ou seja, possui uma intencionalidade. Existe, portanto, uma correlação entre o objeto e a consciência; o primeiro só existe para a segunda (Ribeiro, 1985). Como aponta Frascareli (2010), "nunca existirá uma emoção, por exemplo, em si, mas uma emoção-para-um-sujeito-em-uma-situação" (p. 126). Ou seja, cada atleta tem seu modo de vivenciar sua modalidade, seus relacionamentos, suas dores. Numa mesma equipe, um único fato pode ter reflexos os mais diversos em cada um de seus membros.

Nesse sentido, quando falamos em diagnóstico em gestalt-terapia, não estamos pensando em classificação nosológica, em denominações científicas a priori. O diagnóstico da gestalt-terapia é processual (Frazão, 1991; Pinto, 2015), buscando compreender o significado das queixas, o funcionamento do indivíduo, a figura e o fundo de seus sintomas, acompanhando as mudanças ao longo do tempo. Essas informações complementam-se em relação, constituindo um campo do qual fazem parte a história do atleta, a instituição, a equipe técnica, o psicólogo e inúmeros outros fatores.

Para Frazão (1991), a função do diagnóstico é ajudar a perceber a melhor maneira de trabalhar com cada pessoa. A coleta de informações para a construção deste diagnóstico pode variar de acordo com a necessidade e com o entendimento do psicólogo. Por isso é importante considerar a relação dialógica que se estabelece entre o psicólogo e o atleta: a construção de uma relação genuína e que coloca o outro como sujeito, não como objeto. Esta é uma diferença importante na abordagem gestáltica no esporte, uma vez que não coloca o atleta como objeto de técnicas para aumentar o rendimento, mas sim como um sujeito implicado em sua evolução e desenvolvimento como atleta, que pode usar técnicas a seu favor, compreendendo-as e inserindo-as num contexto.

Na psicologia do esporte, é comum a utilização de testes psicológicos para avaliar os atletas, embora não existam muitos testes voltados à prática esportiva (McCann, Jowdy \& Raalte, 2011). Rubio (2007a) aponta, ainda, que no Brasil a formação dos psicólogos para a construção e uso dos instrumentos é falha, além do fato de que seu uso nem sempre apresenta coerência entre a fundamentação teórica do teste com a abordagem terapêutica utilizada pelo psicólogo. Nesse mesmo sentido, considera- mos muitos testes pouco compatíveis com o olhar gestáltico, pois em geral buscam enquadrar os indivíduos em determinadas categorias preestabelecidas. Como lembra Frascareli (2010), a compreensão psicológica baseada na fenomenologia busca individualizar o sujeito e levar em conta suas especificidades, ao invés de inseri-lo em modelos predeterminados. As coisas não são em si mesmas, mas sim no contexto relacional da existência, tornando incoerente o estabelecimento de leis universais e modelos genéricos, como faz grande parte dos testes utilizados até o momento.

Além disso, muitas das informações reveladas por testes podem ser colhidas a partir de um trabalho de longo prazo, com boas entrevistas e observações dos atletas, contextualizando os comportamentos e apontando os mesmos para os atletas, conscientizando-os de suas ações, como veremos adiante a respeito das formas de intervenção.

De qualquer forma, em alguns momentos os testes são necessários, pois o mundo dos esportes ainda é muito pautado por referenciais concretos e objetivos, tanto por parte dos atletas quanto dos técnicos. Nestes casos, os resultados dos testes podem ser utilizados pelo psicólogo como referência, buscando discrepâncias muito notórias e discutindo seus resultados com o atleta. Além de ser uma obrigação ética e legal, como lembram McCann et al (2011), a devolução dos resultados é um momento precioso para o atleta atribuir sentido à própria avaliação e implicar-se nas ações para modificar o que for necessário. Por exemplo, certa vez uma atleta estava claramente apresentando um quadro de ansiedade, com sintomas físicos, sem conseguir se dar conta disso, mesmo após diversas intervenções. Apenas com o resultado objetivo de um teste de ansiedade ela pôde se conscientizar de sua situação e se abrir para uma intervenção mais profunda, falando sobre o que a angustiava e, principalmente, vivenciando seu problema, o que possibilitou a mudança. Poderíamos dizer, nesse caso, que a devolução do teste foi utilizada como um experimento.

Este momento diagnóstico mais formal possui, ainda, como um de seus resultados, a elaboração de perfis psicológicos, prática comum na Psicologia do Esporte. Trata-se de uma ferramenta importante na área do esporte para interlocução com os demais profissionais, uma das razões apontadas por Pinto (2015) para justificar a elaboração de uma compreensão diagnóstica "formal, sistemática e delimitada”: “...possibilita ao psicoterapeuta não ficar isolado de colegas de outras abordagens ou de outras profissões da área” (p. 32).

Assim, uma forma de aproximar esta prática à abordagem que defendemos aqui é a elaboração de perfis que considerem o aspecto processual do diagnóstico e a plasticidade do ser humano, mostrando tendências, potencialidades e principalmente a possibilidade de mudança, indo de encontro a pedidos recorrentes feitos pelo técnico, como fórmulas para ativação individual, detecção de atletas-problema, receitas para tirar o máximo de desem- 
penho de cada um, a despeito do humano. Um bom perfil é construído após um período de conhecimento deste atleta, de compreensão de sua história familiar e no esporte, seus valores, suas crenças, e considerando não apenas os problemas, mas também os aspectos saudáveis e as potencialidades deste atleta, marcando sempre o aspecto processual, sendo também frequentemente atualizado.

Uma equipe interdisciplinar, de posse destas informações, poderá auxiliar o atleta em sua inteireza, porém sem tirar sua responsabilidade. O gestalt-terapeuta chama o indivíduo para a responsabilidade de sua mudança, acreditando que ele é capaz de resolver seus problemas e dificuldades, não trabalhando, por isso, com o condicionamento. "A responsabilidade por seu comportamento, pela mudança em seu comportamento e pelo trabalho de atingir tal mudança é do paciente” (Yontef, 1998, p. 75).

\section{Parâmetros de intervenção na abordagem gestáltica}

Frascareli (2010) aponta que o fenômeno esportivo, no contexto em que o conhecemos hoje, oferece a possibilidade de compreender o atleta como máquina e mesmo como mero executor, enquanto o técnico, que detém o saber, é aquele capaz de pensar a melhor forma de execução. Nesse sentido, não abre possibilidades para o atleta se apropriar de sua prática, se conhecer e se conscientizar de suas ações. "Desconsiderado em sua percepção e desestimulado a manter-se em contato consigo mesmo abre mão de tornar-se companheiro de si e, em sentido amplo, de conhecer-se" (p. 123)

O objetivo principal do trabalho em gestalt-terapia é exatamente o oposto: 0 aumento da conscientização, da awareness, descobrindo mais recursos para lidar com situações diversas e adversas. Como afirma Yontef (1998, p. 38), a Gestalt-terapia "é mais uma exploração do que uma modificação direta do comportamento. O objetivo é o crescimento e a autonomia, com um aumento da consciência (consciousness)." Mais adiante, acrescenta: "o objetivo não é resolver 'o problema', pois o paciente irá permanecer incapacitado enquanto manipular os outros para resolverem seus problemas, enquanto ele não usar integralmente seu aparelho sensorimotor" (p. 74). Para o autor, enfim, o gestalt-terapeuta não cura nem condiciona; ele é um observador do comportamento e um guia para o aprendizado fenomenológico do indivíduo.

No dia a dia, não é raro identificar atletas que não têm consciência de sua postura, de seus movimentos, de suas reações corporais, de seus sentimentos, enfim, de sua forma de estar e de agir em treinos e competições. Estar alheios a si mesmos os torna mais vulneráveis a fatores externos, podendo sucumbir diante de situações que não seriam tão problemáticas caso estivessem com seu nível de conscientização mais equilibrado. Zinker (2007) elenca alguns atributos que são almejados através do uso da gestalt-terapia individual e clínica, e que podem ser am- pliados no sentido de pensar o ser humano em qualquer ambiente, inclusive no esporte. O foco principal, como foi dito, é desenvolver a awareness, ou seja, a "tomada de consciência global no momento presente, atenção ao conjunto da percepção pessoal, corporal e emocional, interior e ambiental (consciência de si e consciência perceptiva)" (Ginger \& Ginger, 1995, p. 254). Assim, a intervenção focada no aumento da awareness visa a um atleta mais inteiro, integrado e com bom autoconhecimento.

É intenção também que a pessoa aprenda a assumir a autoria de suas experiências e a tomar consciência de suas necessidades, desenvolvendo habilidades para satisfazê-las. A gestalt-terapia busca um contato mais pleno da pessoa com suas emoções, apreciando todos os aspectos de sua existência, e percebendo seu poder pessoal e sua capacidade de dar suporte, sem culpar terceiros nem buscar suporte apenas no meio externo. Por fim, espera-se que a pessoa se torne sensível ao ambiente que a cerca, com capacidade de autoproteção, quando necessária.

Por exemplo, uma das principais ocorrências em atletas é a ansiedade, fato confirmado pela enorme quantidade de publicações científicas investigando o assunto. Porém, embora a compreensão da ansiedade seja fundamental, quando individualizamos o entendimento deste sintoma a abordagem sofre alterações, numa compreensão coerente com a avaliação diagnóstica de que falamos anteriormente. Para a gestalt-terapia, conforme Pinto (2007), a ansiedade patológica está relacionada com o futuro, ligada a expectativas catastróficas ou positivas e à incerteza quanto ao papel a ser desempenhado. Por isso, o "medo do palco" desaparece quando se entra em contato com o presente, deixando de lado a preocupação com o futuro. Assim, num caso de ansiedade pré-competitiva, uma intervenção gestáltica seria ir além da aplicação de técnicas para reduzir os sintomas ansiosos, mas principalmente entender o papel destes: como é competir ansioso, de que forma isso aparece no corpo do atleta. A partir daí, descobrir uma forma de lidar com esses sintomas, que não necessariamente será eliminá-los, pois eles podem estar servindo como um ajustamento criativo para lidar com a dificuldade daquela situação.

Mendonça (2007) descreve o ajustamento criativo como sendo a adaptação do indivíduo ao meio, mantendo sua sobrevivência e seu crescimento de forma responsável. Ao mesmo tempo, ele transforma e é transformado. Assim, um sintoma, visto como um fenômeno, nada mais é do que a adaptação do indivíduo à situação e ao meio em que se encontra, buscando manter-se saudável, embora nem sempre o resultado seja a saúde. Por isso, o simples movimento de ir contra este sintoma fere a autorregulação do organismo, se isolado da tentativa de compreender e ampliar as possibilidades deste indivíduo.

De acordo com a teoria paradoxal da mudança, a mesma só ocorre quando nos tornamos o que somos, não quando tentamos nos tornar o que não somos. Assim, "a mudança não ocorre através de uma tentativa coerciva 
por parte do indivíduo ou de outra pessoa para mudá-lo, mas acontece se dedicarmos tempo e esforço a ser o que somos" (Beisser in Fagan, 1980, p. 110, citado por Orgler, 2007, p. 214). Quando se tem este entendimento, abre-se caminho para a awareness e o contato, provocando mudanças naturais e espontâneas. "A mudança forçada é uma tentativa de concretizar uma imagem, em vez de concretizar o self" (Yontef, 1998, p. 34).

Assim, é possível entender que aqueles sintomas estão aparecendo para transmitir alguma mensagem. Se simplesmente se busca erradicá-los, corre-se o risco de perder algo mais profundo e duradouro, que é decifrar essa mensagem e entender que aquela é a forma possível de competir naquele momento. Da mesma forma, usar a energia vital para brigar com o sintoma pode aumentar o gasto da mesma, quando poderia ser aplicada em prol do rendimento. Saber que vai competir ansioso, nervoso, com tremor nas mãos e desconforto intestinal dá condições de buscar "antídotos" e se aceitar assim, usando essa energia em seu benefício, sem desperdícios e "de maneira que possibilite a completude de seu funcionamento. Ela [a pessoa] age sem dissipar energia, pois aprende a integrar criativamente os sentimentos conflitantes em si mesma, em vez de lutar contra o próprio organismo ou polarizar seu comportamento" (Zinker, 2007, p. 114).

Certa vez, um atleta nos procurou na véspera de uma competição com sintomas físicos de ansiedade: não havia conseguido dormir nem comer adequadamente, estava com as mãos trêmulas, frio na barriga. Procurava uma intervenção imediata que sanasse seus sintomas. $\mathrm{O}$ trabalho com ele, contudo, se iniciou após esta competição, desenvolvendo sua awareness e buscando entender o que o tornava ansioso em momentos pré-competição. Foram descobertos por ele importantes aspectos alheios ao esporte que estavam interferindo em seu comportamento, além de questões do esporte, como ser preterido pela equipe e estar longe de se tornar titular. Competir significava estar no foco, sem ainda estar apto a ter um bom rendimento, sem dominar a prova. Após alguns meses de trabalho de conscientização, de aceitação de sua condição temporária e de experimentos que o permitiram dominar cada vez mais sua prova, o atleta relatou melhora nas competições, pois encontrara estratégias para competir ciente de sua ansiedade. Com isso, "magicamente", em suas próprias palavras, certo dia relatou não se sentir mais ansioso. Ao aceitar os sintomas que seu organismo criou para lidar com uma situação desconfortável, ele conseguiu focar em outras questões, se conhecer melhor e, posteriormente, eliminar os sintomas, chegando à equipe titular e alcançando um desenvolvimento extraordinário em sua modalidade.

Para Zinker (2007), “toda pessoa deve ser capaz de se tornar plenamente consciente (aware) e agir para a satisfação de suas necessidades” (p. 111). A awareness permite à pessoa entender o que está se passando dentro dela e o que fazer para se sentir melhor, fazendo algo a respeito, sem adiar suas necessidades. Essas necessidades são cíclicas e acontecem o tempo todo em nosso organismo, sejam elas de base fisiológica, como a sede ou a fome, ou emocional, ambas sendo satisfeitas através de episódios de contato. $\mathrm{O}$ contato diz respeito à interação do indivíduo com o meio, consistindo na assimilação de algo novo para o organismo e culminando em mudança, que acontece através de "ciclos de encontros e retiradas no campo organismo/meio" (Silveira, 2007, p. 59). Portanto, quando se faz contato, necessariamente há mudança. Como dizem Polster e Polster (1979), não é preciso tentar; a mudança simplesmente ocorre. Logo, o encaminhamento do acompanhamento será feito a partir do ciclo do contato, considerando a necessidade que precisa ser satisfeita.

Quando uma necessidade é atendida, a gestalt que ela organizou se completa e ela não exerce mais influência - o organismo está livre para formar novas Gestalten. Quando essa formação e essa destruição de gestalt estão bloqueadas ou fixas em qualquer etapa, quando necessidades não são reconhecidas e expressas, a harmonia flexível e o fluxo do campo organismo/ ambiente ficam perturbados. Necessidades não-atendidas formam Gestalten incompletas que clamam por atenção e, portanto, interferem na formação de novas Gestalten”. (Yontef, 1998, p. 71)

O contato pode acontecer por completo a partir de determinada experiência ou estar interrompido em alguma de suas fases, o que se configura como mecanismos de resistência ou evitação do contato. Assim, o olhar para o atleta deve ser tanto no momento do atendimento em si, quando ciclos podem ser abertos e fechados, quanto no seu quadro geral cotidiano, em que, numa visão mais macroscópica, pode estar paralisado em alguma fase do ciclo de contato.

Vejamos mais um exemplo prático. Uma atleta de futebol vinha sofrendo uma considerável queda no seu nível de motivação, passando a se atrasar e não se empenhar muito nos treinos e começando a experimentar um humor depressivo. Foi realizada uma investigação de base gestáltica em conjunto com a atleta, através de experimentos e com o objetivo de aumentar sua conscientização sobre o que estava acontecendo. Esta intervenção levou a atleta a perceber que, por mais que se esforçasse, não recebia nenhum tipo de reconhecimento do técnico, nem em forma de elogio nem em forma de crítica construtiva, fazendo com que não tivesse qualquer feedback sobre seu desempenho e se sentisse preterida. A identificação da necessidade deste feedback fez com que a atleta compreendesse melhor seu próprio funcionamento naquele momento e encontrasse estratégias para motivar-se novamente, desobstruindo o fluxo da energia que estava paralisada e abrindo novas possibilidades para si, sem necessariamente esperar que a atitude partisse do técnico. 
Na construção do perfil psicológico do atleta, já citado anteriormente, as principais necessidades do momento são uma informação que pode ser incluída e que consideramos auxiliar bastante a comissão técnica, pois é uma das áreas onde realmente os outros profissionais poderão atuar através de falas, atitudes, treinamentos, encorajamentos, etc., contribuindo para a satisfação das necessidades do atleta.

Vejamos outro exemplo. Um maratonista vem encontrando problemas em seu treinamento devido à preocupação excessiva com os comentários de terceiros sobre sua performance. Ele já conseguiu perceber suas sensações e sentimentos sobre isso, conscientizando-se de que, no momento, é movido pelas opiniões alheias em detrimento de suas próprias opiniões e que muitas vezes suas ações são tomadas no sentido de se defender ou se proteger dos julgamentos. Porém, seu ciclo se interrompe aí. Ele ainda não consegue mobilizar energia para se autossustentar, deixando-se influenciar pelos outros e sofrendo sempre com a queda de autoestima decorrente das críticas. $\mathrm{O}$ trabalho, portanto, vai partir deste ponto, buscando satisfazer sua necessidade de autoconfiança para que se sinta apto a mobilizar energia para não permitir que influências externas o atinjam e interfiram no seu rendimento. Enquanto isso, a consciência de seu modus operandi atual lhe dá tranquilidade para se aceitar e investir em seu processo de mudança.

Outro problema comum em atletas é a falta de estabelecimento de metas ou desejos muito amplos, generalizados, que acabam parecendo inatingíveis. Polster e Polster (1979) afirmam: "uma das formas comuns de ficarmos fora de contato com nossos desejos é aumentá-los, transformá-los em desejos globais, indefiníveis e inatingíveis" (p. 205). Asseguram, ainda, que "quando uma pessoa pode reconhecer e expressar um desejo, ela experiencia um sentimento de estar indo na direção certa e de que conseguirá a sua satisfação" (p. 204). E continuam afirmando que ao se perguntar à pessoa o que ela quer, esse desejo se torna figura, se concretiza, sendo possível identificar os ingredientes necessários para sua realização.

Nesse sentido, o experimento é o antídoto contra o "falar sobre" e para alcançar mudança. O conceito de experimento oferece ao gestalt-terapeuta, em qualquer ambiente, a liberdade para utilizar qualquer recurso que julgue necessário para ampliar a awareness do sujeito, seja ele uma técnica predeterminada ou uma criação do psicólogo. De acordo com Yontef (1998), o gestalt-terapeuta pode usar qualquer método ou técnica desde que o objetivo seja o aumento da awareness e que resulte de diálogo e trabalho fenomenológico.

Na psicologia do esporte, existe uma gama de técnicas conhecidas e largamente utilizadas, como o estabelecimento de metas, visualizações, relaxamentos, diálogo interno, entre muitas outras. Nada impede que o gestaltterapeuta utilize algum destes artifícios como recurso. Porém, se ele os utiliza sob a ótica do experimento, ga- nham outro sentido, que vai além da simples aplicação técnica, mas que se coaduna com a avaliação diagnóstica processual, a relação dialógica, a fenomenologia e a satisfação das necessidades, implicando o atleta na atividade. O psicólogo pode, por exemplo, fazer um relaxamento e, ao perceber uma dificuldade do atleta em se concentrar e relaxar, trabalhar esta dificuldade, investigar junto com o atleta o que está acontecendo, contextualizar junto com ele o significado do ocorrido, ao invés de prescrever mais exercícios diários até que ele consiga atingir a meta, adestrando-se a relaxar.

Assim, o experimento busca tornar a racionalização e a explicação em ação, trazendo para o presente situações ocorridas em qualquer tempo. Ele "é a pedra angular do aprendizado experiencial. Ele transforma o falar em fazer, as recordações estéreis e as teorizações em estar plenamente presente aqui, com a totalidade da imaginação, da energia e da excitação" (Zinker, 2007, p. 141).

$\mathrm{O}$ experimento exige uma postura ativa do sujeito e o ajuda a enxergar novas formas de ver e lidar com suas questões, com a segurança e o suporte do psicólogo que o acompanha e a partir de suas próprias conclusões e interpretações.

Zinker (2007) aponta, com relação à clínica, como propósitos de longo prazo do experimento: o aumento do alcance da awareness, ampliação do entendimento sobre si mesmo, expansão da liberdade de agir com eficiência no ambiente e aumento do repertório de comportamentos em diversas situações de vida. Mais especificamente, complementa:

expandir o repertório de comportamentos da pessoa; criar condições nas quais ela possa ver a vida como sua criação pessoal (assumindo a autoria de sua terapia); estimular o aprendizado experiencial da pessoa e a evolução de novos autoconceitos com base em criações comportamentais; completar situações inacabadas e superar bloqueios/interrupções no ciclo awareness-excitação-contato; integrar compreensões corticais com expressões motoras; descobrir polarizações que não estão na awareness; estimular a integração de forças conflitantes na personalidade; desalojar e reintegrar introjeções e sentimentos, ideias e atos geralmente 'mal situados', instalando-os nos pontos adequados dentro do sistema da personalidade; estimular circunstâncias nas quais a pessoa possa sentir e agir com mais força e competência, de maneira mais exploratória e ativamente responsável, oferecendo suporte a si mesma. (Zinker, 2007, p. 144)

A utilização de técnicas da psicologia do esporte como experimento e a liberdade de criação de tantas outras possibilidades de intervenção com esse objetivo se coaduna com o olhar fenomenológico, que vê o processo único que cada um experiencia; se diferencia do uso de técnicas prontas, fechadas, necessitando e permitindo explorar pos- 
sibilidades. Quando um técnico nos encaminha um atleta com determinada queixa, e se iniciamos o acompanhamento a partir deste a priori, corremos o risco de perder todas as outras possibilidades de sua existência. Trabalhando fenomenologicamente, pelo contrário, esta demanda será investigada, percebendo-se aquilo que aparece no discurso e no comportamento deste atleta. Apenas a investigação destes "sintomas" em conjunto com o próprio atleta pode dar a resposta exata para o que está acontecendo. O que importa, aqui, é a qualidade da observação e o trabalho com o fenômeno tal como ele se apresenta, confirmando aquilo que é óbvio aos olhos com aquele que vivencia a experiência. As possibilidades são infinitas.

Além disso, o setting da psicologia do esporte, para além do consultório, são as pistas, quadras, campos e piscinas. Diversos experimentos podem se originar do próprio esporte que é praticado, permitindo a real experimentação de diversas situações in loco e apresentando novas soluções no ambiente mesmo que o fenômeno acontece. Para isso, o gestalt-terapeuta, todo o tempo, volta a atenção do atleta para si próprio, percebendo suas sensações e sentimentos e imbuindo-o de autonomia para lidar com a situação.

De maneira geral, portanto, vemos que a intervenção tem como parâmetros não apenas os conhecimentos específicos de psicologia do esporte, mas também pode se enriquecer muito a partir das bases filosóficas e metodologia da gestalt-terapia. Assim, ao mesmo tempo em que individualiza, e justamente por isso, amplia o leque de opções de forma infinita.

\section{Considerações finais}

Consideramos que a busca por uma boa forma de fazer psicologia do esporte a partir da abordagem gestáltica encontra-se ainda em seu estágio inicial, tendo surgido muito recentemente. Com a bibliografia nesta área ainda escassa, o intuito deste artigo foi, portanto, de levantar questões iniciais sobre as relações entre a abordagem gestáltica e o esporte, merecendo novos desdobramentos e aprofundamentos em seus diversos níveis de intervenção. Acreditamos, por exemplo, que a compreensão diagnóstica processual dos atletas carece de fundamentação nesta abordagem e pode ainda ser bastante desenvolvida, em especial a partir do ciclo do contato. Da mesma forma, outras formas de intervenção, outros exemplos e aprofundamentos teóricos se fazem urgentes, visto que vem crescendo o interesse de graduandos e profissionais da psicologia nesta prática.

Da mesma forma, existem muitos outros espaços de atuação na psicologia do esporte para além do alto rendimento individual, que foi abordado neste trabalho. Cada um deles certamente apresentará suas especificidades, sendo importante construir material científico sobre cada uma destas possibilidades.
No entanto, julgamos também que este esboço inicial apresenta um panorama das diretrizes principais do trabalho, que são semelhantes em qualquer uma dessas áreas: trabalhar o ser humano de uma forma holística, sem compartimentá-lo em corpo e mente, acreditando nas suas potencialidades e visando seu crescimento pessoal como um todo. Realizar um trabalho contínuo, que embora tenha sido apresentado didaticamente em momentos distintos, acontece ininterruptamente, seguindo a dinâmica de crescimento pessoal de cada pessoa atendida e cuidando para não cair em armadilhas que nos levam de volta ao modelo biomédico.

Acreditamos, também, que uma das principais dificuldades da implementação desta proposta é que não pode ser imediatista, pois apresenta resultados a médio e longo prazos. A abordagem gestáltica no esporte trata de uma transformação mais global do atleta, que não diz respeito apenas a problemas pontuais, constituindo uma preparação psicológica e não apenas um treinamento mental. Insere as questões do esporte no contexto da vida do atleta e de suas relações com o ambiente. Dessa forma, pode ser vista por alguns como inviável ou pouco aplicável ao esporte, por se tratar de um campo que requer resultados rápidos.

Pelo contrário, acreditamos que a gestalt-terapia e a psicologia do esporte prometem um casamento muito promissor, deixando de reduzir o atleta a resultados, mas alcançando os mesmos através de uma mudança mais profunda e humana. O mundo do esporte não está muito acostumado a esta mentalidade, mas cabe ao psicólogo esclarecer que demandas podem ou não ser atendidas e de que forma, sem se cobrar dar conta de exigências que violam o ser humano.

\section{Referências}

Brandão, M. R. F. \& Casal, H. V. (2007). Modelos de prática profissional na Psicologia do Esporte. In M. R. F. Brandão \& A. A. Machado (Org.). Coleção Psicologia do Esporte e do Exercício: teoria e aplicação. (Cap. 3, p. 59-70). Rio de Janeiro: Atheneu.

Carvalhaes, João. (1974). Um psicólogo no futebol: relatos e pesquisas. São Paulo: Esporte e Educação.

Ducasse, François (2006). Cabeça de campeão: como a psicologia forma vencedores no esporte e na vida. Rio de Janeiro: Casa da Palavra.

Esch, C. F. (2012). Descortinando o passado para vislumbrar o porvir: da gestalt-terapia à abordagem gestáltica no Brasil: 40 anos de histórias. Dissertação de Mestrado. Universidade do Estado do Rio de Janeiro, Rio de Janeiro, RJ, Brasil.

Espírito Santo, A. A. do (2005). O que faz um psicólogo no esporte? Mapeando um campo de atuação da Psicologia no Brasil. Monografia de Graduação. Universidade do Estado do Rio de Janeiro, Rio de Janeiro, RJ, Brasil. 
Frascarelli, L. (2010). Os "problemas psicológicos" do atleta: um olhar fenomenológico para a experiência esportiva. Revista Brasileira de Psicologia do Esporte, 3(4), 115-129. Recuperado em 05 de abril, 2013, de http://pepsic.bvsalud.org/pdf/ rbpe/v3n1/v3n1a08.pdf.

Frazão, L. M. (1991). Pensamento diagnóstico em gestalt-terapia. Insight-psicoterapia, São Paulo, 4, 14-16.

Ginger, S. \& Ginger, A. (1995). Gestalt: uma terapia do contato. (S. S. Rangel, Trad.). São Paulo: Summus. (Original publicado em francês, 1987).

Haddock Lobo, R. (1973). Psicologia dos esportes. São Paulo: Atlas.

Juliano, J. C. (2004). Gestalt-terapia: revisitando as nossas histórias. IGT na Rede, 1(1). Recuperado de 04 de julho, 2011, de: http://www.igt.psc.br/ ojs/viewarticle.php?id=33.

Markunas, M. (2003). Periodização da preparação e do treinamento psicológico. In K. RUBIO (Org.). Psicologia do esporte: teoria e prática. (Cap. 2, p. 33-56). São Paulo: Casa do Psicólogo.

McCann, S. C., Jowdy, D. P. \& Van Raalte, J. L. Avaliação em psicologia do esporte. (2011). In J. L. Van Raalte \& B. W. Brewer. Psicologia do esporte. (H. T. Buchup, Trad.) (Cap. 14, p. 291-305). São Paulo: Santos. (Original publicado em inglês, 2002).

Mendonça, M. M. (2007). Ajustamento criativo. In G. D’Acri, P. Lima \& S. Orgler (Eds.). Dicionário de gestalt-terapia: "gestaltês". (p. 20-22). São Paulo: Summus.

Orgler, S. (2007). Teoria paradoxal da mudança. In G. D’Acri, P. Lima \& S. Orgler (Eds.). Dicionário de gestalt-terapia: "gestaltês” (p. 214-215). São Paulo: Summus.

Pinto, E. B. (2007). Ansiedade. In G. D’Acri, P. Lima \& S. Orgler (Eds.). Dicionário de gestalt-terapia: "gestaltês". (p. 22-24). São Paulo: Summus.

Pinto, E. B. (2015). Elementos para uma compreensão diagnóstica em psicoterapia: o ciclo do contato e os modos de ser. São Paulo: Summus Editorial.

Polster, M. \& Polster, E. (1979). Gestalt-terapia integrada. (R. B. Rocha, Trad.). Belo Horizonte: Interlivros. (Original publicado em inglês).

Prestrelo, E. T. (2001). A história da Gestalt-Terapia no Brasil: "peles-vermelhas" ou “caras-pálidas”? In A. M. Jacó-Vilela, A. C. Cerezzo \& H. B. C. Rodrigues (Orgs.). Clio-psyché hoje: fazeres e dizeres psi na história do Brasil. (p. 87-93). Rio de Janeiro: Relume Dumará: FAPERJ.

Ribeiro da Silva, A. (1967). Psicologia esportiva e preparo do atleta. Rio de Janeiro: Fundação Getúlio Vargas.

Ribeiro, J. P. (1985). Gestalt-terapia: refazendo um caminho. São Paulo: Summus.

Rubio, K. (2007a). A avaliação em Psicologia do Esporte e a busca de indicadores de rendimento. In K. Rubio \& L. F. Angelo (org.). Instrumentos de avaliação em Psicologia do Esporte. (p. 13-26). São Paulo: Casa do Psicólogo.
Rubio, K. (2007b). Da psicologia do esporte que temos à psicologia do esporte que queremos. Revista Brasileira de Psicologia do Esporte, 1(1). Recuperado em 04 de julho, 2011, de http://pepsic.bvsalud.org/scielo.php?script=sci arttext\&pid=S1981-91452007000100007\&lng=pt\&nrm = iso.

Silveira, T. M. (2007). Contato. In G. D’Acri, P. Lima \& S. Orgler (Eds.). Dicionário de gestalt-terapia: "gestaltês" (p. 59-60). São Paulo: Summus.

Tellegen, T. A. (1972). Elementos de psicologia gestáltica. Boletim de Psicologia, XXIV, 64, p. 27-42.

Weinberg, R. S.; Gould, D. (2008). Fundamentos da Psicologia do Esporte e do Exercício. (4 ${ }^{\mathrm{a}}$ ed.). (C. Monteiro, Trad.). Porto Alegre: Artmed. (Original publicado em inglês, 2001).

Yontef, G. M. (1998). Processo, diálogo e awareness: ensaios em gestalt-terapia. (3. ed.). (E. Stern, Trad.). São Paulo: Summus. (Original publicado em inglês, 1993).

Zinker, J. (2007). Processo criativo em Gestalt-terapia. (M. S. Mourão Netto, Trad.). São Paulo: Summus. (Original publicado em inglês, 1977).

Adriana Amaral do Espírito Santo - Possui Licenciatura em Psicologia, Formação de Psicólogo e Bacharelado em Psicologia pela Universidade do Estado do Rio de Janeiro (UERJ), Doutora em Psicologia Social pela Universidade do Estado do Rio de Janeiro (UERJ), psicóloga do esporte no Centro de Educação Física Almirante Adalberto Nunes (CEFAN) da Marinha do Brasil.E-mail: adriana_aes@hotmail.com

Recebido em 21.01.16 Primeira Decisão Editorial em 01.04.16 Segunda Decisão Editorial em 04.06.16 Aceito em 20.10 .16 